\title{
Lipid dysregulation in seminal and follicular fluids could be related with male and female infertility
}

\begin{abstract}
There is evidence which supports the role of lipids in male and female infertility. Lipids are involved in basic molecular processes for reproduction, such as cholesterol, which is the main substrate for steroid synthesis and has been shown to affect the hormonal milieu and steroidogenesis in both men and women. However, its association with male and female infertility was still not clear. Association's in-between lipid levels in seminal plasma with semen parameters and cholesterol levels in follicular fluid with ovarian reserve showed no clear correlation.
\end{abstract}

The aim of this study was to assess the total levels of cholesterol, triglycerides (TG) and non-esterified fatty acids (NEFA) in serum, seminal and follicular fluid of infertile men and women comparing with healthy controls.

Semen samples from 20 patients attending the Andrology Laboratory in Clinica Tambre with low sperm count and motility were included in this study. A control group was formed by 39 fertile men with normal semen parameters. Follicular fluid (FF) was obtained from 14 patients $<35$ years old, low responders ( $\leq 5$ oocytes retrieved) undergoing IVF (in vitro fertilisation) and 40 healthy fertile oocyte donors, both under the same ovarian stimulation protocol. The total levels of cholesterol, triglyceride (TG) and non-esterified fatty acids (NEFA) were determined by commercial kits. T-Student test was used to verify normality distribution of the variables. One-way-ANOVA was used to compare the differences among the three groups.

In the group of male patients, the levels of TG and NEFA in seminal fluids and TG in plasma were significantly elevated as compared to the control group. TG in follicular fluid and NEFA concentrations in serum and follicular fluid were significantly higher in patients with low response in comparison to the control group.

In conclusion, altered sperm parameters and low ovarian reserve are associated with elevated triglycerides and fatty acids in seminal plasma and ovarian follicular fluid. Gamete maturation within this lipid-rich environment is detrimental to spermatozoa and oocytes.
Volume 6 Issue I - 2018

Rocio Nunez Calonge,' Roman Kireev, ${ }^{2}$ Andres Guijarro, ${ }^{3}$ Susana Cortes,' Carolina Andres,' Pedro Caballero'

'Reproduction Unit, Clínica Tambre, Spain

${ }^{2}$ Galicia Sur, Health Research Institute, Spain

${ }^{3}$ Hospital Virgen de la Luz, Spain

Correspondence: Rocio Nunez Calonge, Clinica Tambre, Tambre 8, 28002 Madrid, Spain, Tel +34 629152399,

Email rocio@clinicatambre.com

Received: December 22, 2017 | Published: February 06, 2018

Keywords: male infertility, female infertility, lipids

Abbreviations: TG, triglycerides; NEFA, non-esterified fatty acids; FF, follicular fluid; HDL, high-density lipoprotein; LR, low responders

\section{Introduction}

The role of lipids in male and female fertility is extensively supported in the literature. ${ }^{1-8}$ Increased high-density lipoprotein (HDL) concentrations have been associated with better oocyte and embryo outcomes. ${ }^{3,4}$ as well as being correlated with beneficial effects on spermatogenesis. ${ }^{9,10}$ Hypothesis on the role of lipids in human reproduction have also arisen as cholesterol is the main substrate for steroid synthesis. ${ }^{1}$ which, in fact, has been shown to affect the hormonal milieu and steroidogenesis in both men and women. ${ }^{5}$

On the one hand, abnormal lipid metabolism is closely associated with spermatogenesis, sperm maturation and capacitation disorders when evaluating male subjects. ${ }^{11,12}$ On the other hand, regarding the female population, oocytes developing within ovarian follicles grow rapidly and require supply of energy and cholesterol. ${ }^{13}$ Oocytes are surrounded by follicular fluid (FF) that, in contrast to human plasma, mainly contains HDL cholesterol which is in fact the smallest lipoprotein subclass. ${ }^{14}$ Even though expression of the LDL receptor as well as the LDL receptor-related protein 4 has been reported in mammalian oocytes, ${ }^{15}$ most of the research has focused on HDL within FF.

The aim of this study was to assess the total levels of cholesterol, triglyceride (TG) and non-esterified fatty acids (NEFA) in serum, seminal and follicular fluid of infertile men and women comparing with healthy controls.

\section{Materials and methods}

This prospective clinical study was conducted at Clinica Tambre from February 2017 to June 2017. It was approved by the Ethical Review Board of the Hospital de la Princesa (Madrid, Spain).

\section{Male patients}

Semen samples were obtained from 20patients (aged in between $28=46$ years old) classified as oligoasthenoteratozoospermic $(\mathrm{OATz})$ according to WHO 2010 criteria, who attended the Andrology 
Laboratory in Clinica Tambre. ${ }^{16}$ Patients included in the study had to meet the following inclusion criteria: non-azoospermic patients with a normal 46, XY karyotype evaluated by conventional cytogenetic analysis, normal hormone profile, no history of radiotherapy, chemotherapy, chronic illness or medication, and patients without sperm defects genetically originated. Physical examination and scrotal Eco-color Doppler were performed on all patients to detect the presence of varicocele. To identify the presence of clinically asymptomatic genitourinary infections, a bacteriological analysis was performed on all semen samples. All infertile patients were individuals who did not obtain pregnancy after 2 years of unprotected sexual intercourse.

The control group was formed by 39men with proven fertility as sperm donors in Clinica Tambre. Fertile men (aged in-between 24-40years old) with normal karyotype and semen parameters $>25$ percentile. ${ }^{16}$ and not affected by anatomical problems and/or infections. All patients gave informed consent for this research.

\section{Semen analysis}

Semen samples were collected by masturbation after a period of $3-5$ days of sexual abstinence. After liquefaction $\left(37^{\circ} \mathrm{C}, 30 \mathrm{~min}\right)$, smears of neat semen were prepared for sperm morphology assessment and sperm concentration and motility were evaluated according to the WHO criteria. ${ }^{16}$

\section{Female patients}

Follicular fluids (FF) were obtained from 14patients $<35$ years old, low responders (LR) ( $\leq 5$ oocytes retrieved after follicular punction) undergoing IVF and 40 healthy fertile oocyte donors, both under the same ovarian stimulation protocol.

Patients were recruited according to the following criteria:

i. Absence of any apparent abnormality in the reproductive system, revealed by their medical history, clinical examinations and common hormonal tests;

ii. Absence of any metabolic or endocrine system-associated diseases, such as hyperprolactinaemia, thyroid dysfunction or polycystic ovary syndrome defined by the Rotterdam criteria (Rotterdam ESHRE/ASRM-Sponsored PCOS Consensus Workshop Group, 2004); ${ }^{17}$

iii. Absence of any surgical history regarding the reproductive system;

iv. Normal ovulatory cycle, with cycle lengths in between 25 and 35days;

v. Aged in between 28 and 35years old;

vi. Body mass index (BMI) in between 19 and $26 \mathrm{~kg} / \mathrm{m}^{2}$; and

vii. Absence of any kind of smoking history. Patients gave written informed consent and did not receive any monetary compensation for participating in the study. ${ }^{18}$

Women were included as donors after being thoroughly informed about oocyte donation and later fully evaluated to assess fulfillment of the criteria required to be admitted into a donation program. In short, oocyte donors were in between 18-35years old. Complete medical history examination was performed, which had to include absence of current or past exposure to radiation or hazardous chemical substances, drug abuse and past reproductive history. All donors must had had, as a result of the exhaustive evaluation, a normal physical and gynecological examination, BMI in between 19 and $26 \mathrm{~kg} / \mathrm{m}^{2}$, no family history of hereditary or chromosomal diseases, normal karyotype and negative screening for sexually transmitted diseases (STD).$^{19}$

\section{Ovarian stimulation protocols}

Ovarian stimulation in patients was initiated with 225-300UI/ day rec-FSH (Gonal-F®; Merck, Madrid, Spain) from day 2 of the menstrual cycle. The GnRH antagonist (Cetrotide; Merck, Madrid, Spain) was introduced according to a multiple-dose protocol $(0.25 \mathrm{mg} /$ day $)$ when a leading follicle of $14 \mathrm{~mm}$ and/or oestradiol concentrations of $400 \mathrm{pg} / \mathrm{ml}$ was reached. Recombinant human chorionic gonadotrophin (HCG) (Ovitrelle ${ }^{\circledR}$, Merck, Madrid, Spain) was applied when $\geq 2$ follicles reached $\geq 17 \mathrm{~mm}$ and oocyte retrieval was performed under sedation at the $36^{\text {th }}$ hour following HCG.

The ovarian stimulation in donors began with 125-225IU of recombinant FSH (Gonal-F®; Merck Serono, Madrid, Spain) from day 2 of the menstrual cycle. The GnRH antagonist (Cetrotide; Merck, Madrid, Spain) was introduced according to a multipledose protocol $(0.25 \mathrm{mg} /$ day $)$ when a leading follicle of $14 \mathrm{~mm}$ and/or oestradiol concentration of $400 \mathrm{pg} / \mathrm{ml}$ was reached. Triggering was performed when at least three follicles $>17 \mathrm{~mm}$ were present with $0.2 \mathrm{mg}$ of triptorelin (SC Decapeptyl, Ipsen Pharma, Barcelona, Spain) and oocyte retrieval was performed under sedation at the 36th hour following GnRHa. In all groups, the first control (ultrasonography and serum oestradiol) was performed after 5days of stimulation, and the daily dose of FSH was adjusted individually according to the ovarian response.

\section{Seminal, follicular and blood plasma sample preparation}

Seminal plasma was obtained by centrifuging the semen samples at $300 \mathrm{~g}$ for $7 \mathrm{~min}$ at room temperature. Samples were stored in liquid nitrogen. At the time of semen retrieval, $5 \mathrm{ml}$ of fasting blood from each male was placed in an EDTA-coated tube and centrifuged at $600 \mathrm{~g}$ for $15 \mathrm{~min}$ at $48 \mathrm{C}$. For each analysis, $100 \mathrm{ml}$ of blood plasma was added to $0.9 \mathrm{ml}$ of BHA solution and stored in liquid nitrogen.

Oocytes were separated and placed into culture media, whereas follicular fluid was collected in flasks. ${ }^{20}$ Only uncontaminated follicular fluid minimally stained with blood were kept for further determinations. At oocyte retrieval, and after removing the oocytes, follicular aspirates were centrifuged at $600 \mathrm{~g}$ for $10 \mathrm{~min}$ and the supernatant stored at $-70^{\circ} \mathrm{C}$ for a maximum of 2 weeks.

Venous blood samples were placed in an EDTA-coated tube and centrifuged at $600 \mathrm{~g}$ for $15 \mathrm{~min}$ to isolate serum for detection of lipid level.

\section{Total cholesterol, triglyceride (TG) and non-esterified fatty acids (NEFA) acid analysis}

Lipids were separated according to the standard Folch method. ${ }^{21}$ Briefly, $100 \mathrm{ml}$ of sample (blood, follicular fluid or seminal plasma in BHA) was mixed with $1.9 \mathrm{ml}$ of chloroform/methanol $(2: 1 \mathrm{v} / \mathrm{v})$ and $1 \mathrm{ml}$ of cold water. The mixture was vortexed for $90 \mathrm{~min}$ at $48 \mathrm{C}$. From the resulting organic phase, aliquots were then used for phospholipid analysis by thin-layer chromatography (TLC), acid hydrolysis and methylation as described by Schlenk and Gellerman. ${ }^{22}$

Biochemical analyses of TG and total cholesterol were performed as previously described. ${ }^{23}$ Briefly, triglycerides were measured using a glycerol blanked enzymatic method (Trig/GB, Roche Diagnostics 
Corporation, Indianapolis, IN) and cholesterol was measured using a cholesterol esterase, cholesterol oxidase reaction (Chol R1, Roche Diagnostics Corporation) on the Roche/Hitachi 911 Automatic Analyzer (Roche Diagnostics Corporation).

\section{Statistics}

All data were analyzed using SPSS 22.0 software (SPSS Inc., Chicago, IL, USA). First, nonparametric tests (one-sample Kolmogorov-Smirnov test) were used to determine whether parameters were consistent with normal distribution and Pearson correlation coefficients were calculated to assess the correlations. Statistical significance was set at P, 0.05 for all tests.

\section{Results}

\section{General data}

The clinical characteristics of the male study population are represented in Table 1, by age group, BMI $\left(\mathrm{kg} / \mathrm{m}^{2}\right)$, semen volume $(\mathrm{ml})$, total sperm count $\left(10^{6}\right)$, Sperm concentration $\left(10^{6}\right)$, motility $(\%)$ and morphology $(\%)$. There were no significant differences between male study population and controls, except for total sperm count $(p<0.001)$, sperm concentration $(p<0.001)$, motility $(p<0.01)$ and morphology $(p<0.01)$. In fact, the percentage of sperm with normal count, motility and morphology was higher for the control males than for the male study population.

Table I Characteristics of male patients $(n=20)$ and fertile volunteers $(n=39)$ in terms of age, $B M I\left(k g / \mathrm{m}^{2}\right)$, semen volume $(\mathrm{ml})$, total sperm count $\left(I 0^{6}\right)$, sperm concentration $\left(10^{6}\right)$, motility $(\%)$ and morphology $(\%)$. There were no significant differences between male study population and controls, except for total sperm count $(p<0.00 \mathrm{I})$, sperm concentration $(p<0.00 \mathrm{I})$, motility $(p<0.0 \mathrm{I})$ and morphology $(\mathrm{p}<0.0 \mathrm{I})$

\begin{tabular}{llll}
\hline & Male patients $(\mathbf{n}=\mathbf{2 0})$ & Sperm donors $(\mathbf{n}=\mathbf{3 9})$ & P value \\
\hline Age $($ Years $)$ & $35.5 \pm 10$ & $32.0 \pm 12$ & NS \\
BMl $\left(\mathrm{kg} / \mathrm{m}^{2}\right)$ & $22.1 \pm 4$ & $23.1 \pm 6$ & $\mathrm{NS}$ \\
Semen volume $(\mathrm{ml})$ & $3.2 \pm 1$ & $2.85 \pm 1.5$ & $\mathrm{NS}$ \\
Total sperm count $\left(\times 10^{6}\right)$ & $34 \pm 3,5$ & $156 \pm 19$ & 0.001 \\
Sperm concentration $\left(\times 10^{6}\right)$ & $10,2 \pm 4,1$ & $87 \pm 15$ & 0.001 \\
Motility $(\%)$ & $24 \pm 6$ & $58 \pm 10$ & 0.01 \\
Normal morphology $(\%)$ & $3 \pm 1$ & $35 \pm 10$ & 0.01 \\
\hline
\end{tabular}

Values are mean \pm SD

BMI, body mass index

The clinical characteristics of the female study population are represented in Table 2, by age group and response levels in terms of BMI $\left(\mathrm{kg} / \mathrm{m}^{2}\right)$ anti-Müllerian hormone $(\mathrm{AMH})$, amount of basal $\mathrm{FSH}$, amount of administered FSH, the oestradiol value on the day of $\mathrm{hCG} / \mathrm{GnRH}$ injection and number of oocytes retrieved. No statistical difference was found in the amount of total gonadotrophin used for ovarian stimulation in poor responders compared with the non-poor responders group. Serum oestradiol concentrations on the day of the
HCG injection were lower in poor responders $(\mathrm{P}=0.01)$ (Table 2). As the response levels were defined according to oocyte numbers, the number of retrieved oocytes was significantly different in between the poor and non-poor responders $(\mathrm{P}=0.001)$.

The value of Estradiol ${ }^{\mathrm{a}}$ and number of retrieved oocytes ${ }^{\mathrm{b}}$ are significantly different among the poor and non-poor responder patients.

Table 2 Patients characteristics in the low responders ( $<5$ oocytes) $(n=14)$, and control groups (oocyte donors) $(n=40)$ in terms of $B M I\left(k g / m^{2}\right)$ anti-Müllerian hormone (AMH), amount of basal FSH, amount of administered FSH, the oestradiol value on the day of hCG/GnRH injection and number of oocytes retrieved No statistical difference was found in the amount of total gonadotrophin used for ovarian stimulation in poor responders compared with the non-poor responders group. Serum oestradiol concentrations on the day of the HCG injection were lower in poor responders $(P=0.0 \mathrm{I})$. As the response levels were defined according to oocyte numbers, the number of retrieved oocytes was significantly different in between the poor and non-poor responders $(P=0.00 \mathrm{I})$

\begin{tabular}{llll}
\hline & Female patients $(\mathbf{n}=14)$ & Oocyte donors $(\mathbf{n}=40)$ & P-value \\
\hline Age $($ Years $)$ & $32.4 \pm 2.1$ & $29.4 \pm 4.1$ & NS \\
BMI $\left(\mathrm{kg} / \mathrm{m}^{2}\right)$ & $22.5 \pm 2.1$ & $21.4 \pm 1.3$ & NS \\
AMH $(\mathrm{ng} / \mathrm{ml})$ & $3.66 \pm 1.2$ & $4.74 \pm 1.3$ & $\mathrm{NS}$ \\
Basal FSH $(\mathrm{IU} / \mathrm{l})$ & $5.2 \pm 1.2$ & $5.7 \pm 3.2$ & $\mathrm{NS}$ \\
Total FSH administered $(\mathrm{IU})$ & $1877 \pm 158$ & $1962 \pm 146$ & $\mathrm{NS}$ \\
E2 value of hCG/GnRH day $(\mathrm{pg} / \mathrm{ml})$ & $1547 \pm 198 \mathrm{a}$ & $2473 \pm 361$ & 0.01 \\
Total oocytes retrieved & $3.2 \pm 1.3 \mathrm{~b}$ & $11.5 \pm 3.8$ & 0.001 \\
\hline
\end{tabular}

Values are mean $\pm S D$

BMI, body mass index

$\mathrm{AMH}$, anti-mullerian hormone 
Relationship between lipids levels in serum and seminal plasma of male patients and sperm donors

Subjects with low sperm motility and sperm concentration had higher median serum lipid concentrations than those without sperm alterations. In the group of patients, the levels of TG and NEFA in seminal fluids and TG in plasma were significantly elevated as compared to the control group (TG: $91.1 \pm 7.3 \mathrm{mg} / \mathrm{dl}$ in serum donors and $164.3 \pm 18.7 \mathrm{mg} / \mathrm{dl}$ in serum patients, $\mathrm{p}<0.01 ; 93.6 \pm 8.94 \mathrm{mg} / \mathrm{dl}$ in seminal plasma donors and $200.3 \pm 53.36 \mathrm{mg} / \mathrm{dl}$ in seminal plasma patients, $\mathrm{p}<0.01$; NEFA: $7.8 \pm 0.078 \mathrm{mg} / \mathrm{dl}$ in seminal plasma donors and $11.4 \pm 0.097 \mathrm{mg} / \mathrm{dl}$ in seminal plasma patients) (Figures $1 \& 2$ ).
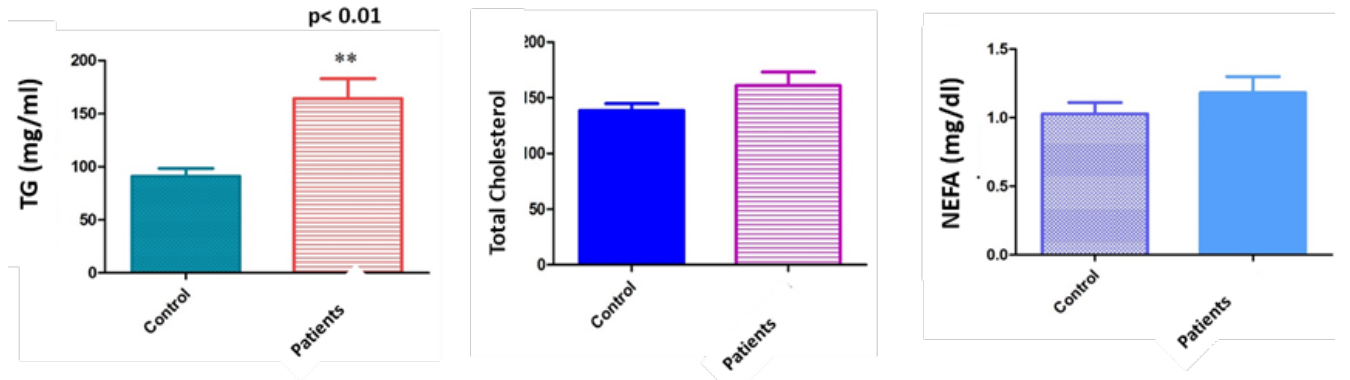

Figure I Level of lipids profile (TG, cholesterol and NEFA) in serum of male patients compared with controls (sperm donors). Male patients had higher median serum lipid concentrations than those without sperm alterations. In the group of patients, the levels of TG in plasma were significantly elevated as compared to the control group (TG: $91.1 \pm 7.3 \mathrm{mg} / \mathrm{dl}$ in serum donors and $164.3 \pm 18.7 \mathrm{mg} / \mathrm{dl}$ in serum patients, $\mathrm{p}<0.01$; No statistically significant differences were observed in between total cholesterol levels in serum from patients and sperm donors. Likewise, no correlation was either found in between NEFA levels in serum and sperm quality.
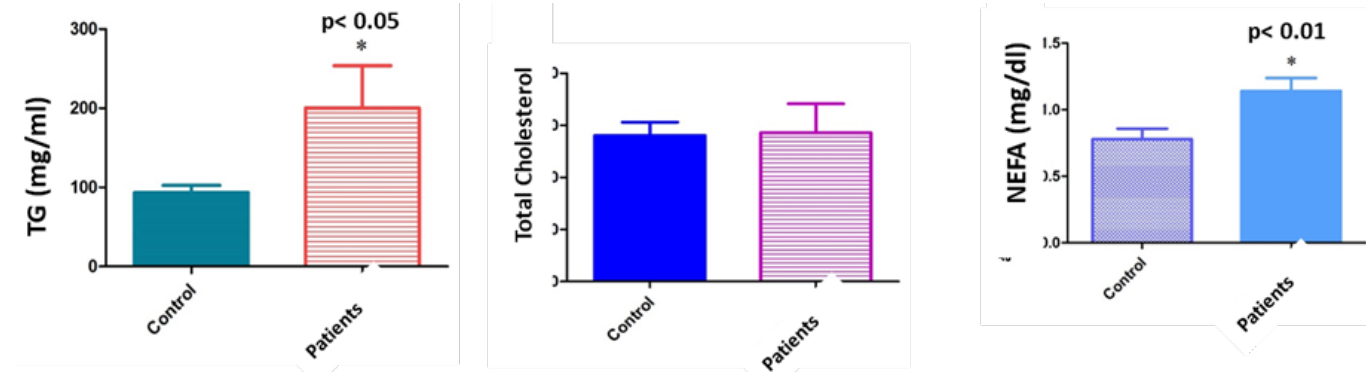

Figure 2 Level of lipids profile (TG, cholesterol and NEFA) in seminal plasma of male patients compared with controls (sperm donors). In the group of patients, the levels of TG and NEFA in seminal fluids were significantly elevated as compared to the control group $(93.6 \pm 8.94 \mathrm{mg} / \mathrm{dl}$ in seminal plasma donors and $200.3 \pm 53.36 \mathrm{mg} / \mathrm{dl}$ in seminal plasma patients, $\mathrm{p}<0.01$; NEFA: $7.8 \pm 0.078 \mathrm{mg} / \mathrm{dl}$ in seminal plasma donors and II.4 $\pm 0.097 \mathrm{mg} / \mathrm{dl}$ in seminal plasma patients). No statistically significant differences were observed in between total cholesterol levels in seminal plasma from patients and sperm donors.

No statistically significant differences were observed in between total cholesterol levels in serum or seminal plasma from patients and sperm donors. Likewise, no correlation was either found in between NEFA levels in serum and sper.

\section{Relationship between lipid levels in serum and follicular fluid of female patients and oocyte donors}

TG in follicular fluid and NEFA concentrations in serum and follicular fluid were significantly higher in patients with low response

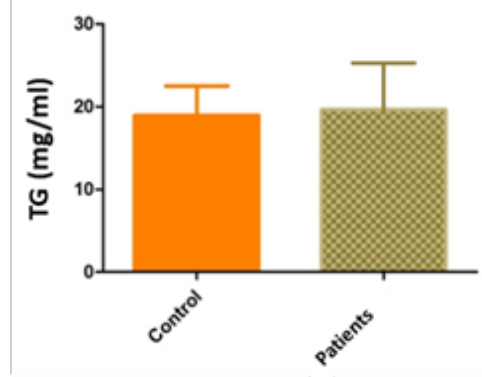

than in the control group. (TG: $100.8 \pm 8.25 \mathrm{mg} / \mathrm{dl}$ in follicular fluid donors and $137.1 \pm 10.47 \mathrm{mg} / \mathrm{dl}$ in follicular fluid patients, $\mathrm{p}<0.01$; NEFA: $3.5 \pm 0.035 \mathrm{mg} / \mathrm{dl}$ in FF donors and $6 \pm 0.1 \mathrm{mg} / \mathrm{dl}$ in FF patients; $3.1 \pm 0.013 \mathrm{mg} / \mathrm{dl}$ in serum donors and $4.7 \pm 0.08 \mathrm{mg} / \mathrm{dl}$ in serum patients) (Figures 3\&4).

No statistically significant differences were observed in between total cholesterol levels in serum neither in FF from young women with LR and oocyte.
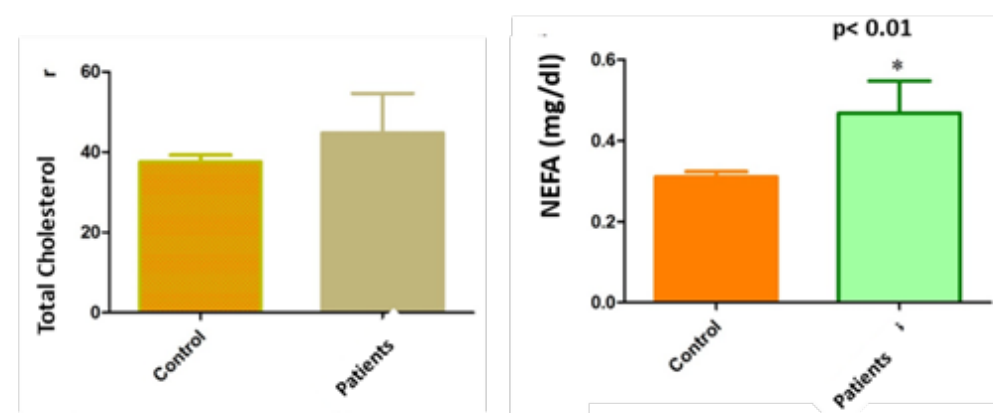

Figure 3 Level of lipids profile (TG, cholesterol and NEFA) in serum of female patients compared with controls (sperm donors). NEFA concentrations in serum were significantly higher in patients with low response than in the control group. $(3.1 \pm 0.013 \mathrm{mg} / \mathrm{dl}$ in serum donors and $4.7 \pm 0.08 \mathrm{mg} / \mathrm{dl}$ in serum patients). No statistically significant differences were observed in between TG and total cholesterol levels in serum from young women with LR and oocyte. 

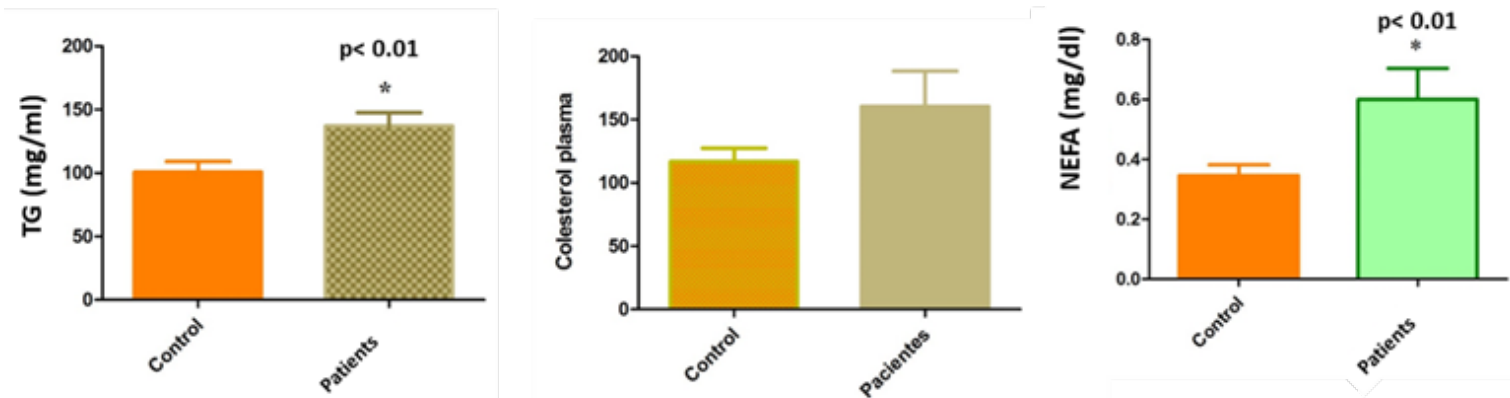

Figure 4 Level of lipids profile (TG, cholesterol and NEFA) in follicular fluid of female patients compared with controls (sperm donors).TG in follicular fluid and NEFA concentrations in follicular fluid were significantly higher in patients with low response than in the control group. (TG: $100.8 \pm 8.25 \mathrm{mg} / \mathrm{dl}$ in follicular fluid donors and $137.1 \pm 10.47 \mathrm{mg} / \mathrm{dl}$ in follicular fluid patients, $\mathrm{p}<0.0 \mathrm{I}$; NEFA: $3.5 \pm 0.035 \mathrm{mg} / \mathrm{dl}$ in FF donors and $6 \pm 0.1 \mathrm{mg} / \mathrm{dl}$ in FF patient). No statistically significant differences were observed in between total cholesterol levels in FF from young women with LR and oocyte.

\section{Discussion}

Several studies showed significant correlation in between lipid composition in sperm membrane and seminal plasma. ${ }^{24}$ as well as increased phospholipid levels in seminal plasma in oligospermic and azoospermic patients. ${ }^{25}$ Studies on lipid composition of human testis in patients with bilateral varicocele as cause of infertility showed abundant lipids in the testis tissue. The total amount of lipids was 1.90 percent of the total wet weight of the human testis tissue. Testicular cholesterol, glycerides and phospholipids were 26.50 percent, 28.50 percent and 45percent, respectively, of the total percentage of lipids. ${ }^{26}$ Also abundant cholesterol and phospholipids were found in sperm membranes, ${ }^{27}$ especially polyunsaturated fatty acids (PUFA) closely related to sperm function. ${ }^{28-31}$ During spermatogenesis, sperm maturation, capacitation and acrosome reaction, lipid composition in sperm membranes change significantly. ${ }^{32-34}$ These changes were possibly based on the transfer of cholesterol and phospholipids in between sperm and seminal plasma. ${ }^{35-36}$ However, no clear correlation was found in between lipid levels in serum and seminal plasma with semen parameters.

In the present study, we analyzed the correlation in between lipid levels in serum and seminal plasma and semen parameters in 20 infertile men compared with fertile sperm donors. We have found a correlation in between levels of triglycerides both in serum and sperm, and sperm quality. A relationship was also found in between non esterified fatty acids in seminal plasma and sperm quality, suggesting that male infertility could be influenced by lipid metabolism. However, surprisingly, serum and seminal plasma levels of total cholesterol were unrelated to semen parameters. This observation was similar to the results reported by Hagiuda and colleagues. ${ }^{37}$ The fact that higher concentrations of NEFA were found in seminal plasma but not in blood suggests that Lipid levels may not be originiated from blood/the origin of these lipids might be different to blood. This raises the question about how lipids are originated and regulated in seminal plasma. In fact, it may be possibly originated from epithelial cells in the male reproductive tract.

Further, we analyzed the correlation of lipids levels in serum and follicular fluid with female infertility (number of oocyte and response to ovarian stimulation). The results showed that the level of NEFA in serum as well as in follicular fluid and triglycerides in follicular fluid were slightly higher in patients compared with oocyte donors.

Within a growing follicle in the ovary, the oocyte is surrounded by concentric layers of cells and tissue. These layers are, from the periphery inwards: a. Theca externa;

b. Theca internal;

c. Basal membrane; and

d. Granulosa cells. ${ }^{38}$ The oocyte has, as a rapidly growing cell, a considerable demand of energy as well as lipids. ${ }^{39}$

Our study shows that the level of triglycerides is higher in the follicular fluid of patients with low response than in fertile donors, which can be translated as a malfunction of the follicle in these patients. However, the possibility that granulosa cells secrete triglycerides has not been investigated previously. Our results are in agreement with those published by Robker et al., ${ }^{40}$ which showed a relationship in between obesity and increased triglycerides in the follicular fluid. It is likely that additional factors also associate with high lipid content in follicle fluid and contribute to the dramatic effects on oocyte maturation. For instance, inflammatory mediators and oxidative stress are elevated in the follicular fluid of obese women and, as we demonstrated, in low responders patients.

Our study reveals that lipid levels in follicular fluid vary remarkably between women. Also that differing levels of these lipids, and presumably many additional cofactors in follicular fluid, can exert dramatically different effects, as previously showed by Yang et al. ${ }^{41}$

Lipids levels in the patient group (both, men and women) are superior to the control group probably due to a compensatory mechanism caused by a possible increase in oxidative stress.

\section{Conclusion}

In conclusion, altered sperm parameters and low ovarian reserve are associated with elevated triglycerides and fatty acids in seminal plasma and ovarian follicular fluid. Gamete maturation within this lipid-rich environment is detrimental to spermatozoa and oocytes.

\section{Acknowledgements}

None.

\section{Conflicts of interest}

The authors declare that there is no conflict of interest.

\section{Funding}

None. 


\section{References}

1. Miller WL, Auchus RJ. The molecular biology, biochemistry, and physiology of human steroidogenesis and its disorders. Endocr Rev. 2011;32(1):81-151.

2. Gwynne JT, Strauss JF. The role of lipoproteins in steroidogenesis and cholesterol metabolism in steroidogenic glands. Endocr Rev. 1982;3(3):299-329.

3. Cardozo E, Pavone ME, Hirshfeld-Cytron JE. Metabolic syndrome and oocyte quality. Trends Endocrinol Metab. 2011;22(3):103-109.

4. Fujimoto VY, Kane JP, Ishida BY, et al. High-density lipoprotein metabolism and the human embryo. Hum Reprod Update. 2010;16(1):20-38.

5. Grummer RR, Carroll DJ. A review of lipoprotein cholesterol metabolism: importance to ovarian function. J Anim Sci. 1988;66(12):3160-3173.

6. Lobaccaro JM, Gallot D, Lumbroso S, et al. Liver X receptors and female reproduction: when cholesterol meets fertility!. J Endocrinol Invest. 2013;36(1):55-60.

7. Maqdasy S, Baptissart M, Vega A, et al. Cholesterol and male fertility: what about orphans and adopted? Mol Cell Endocrinol. 2013;368(1-2):30-46.

8. Miettinen HE, Rayburn H, Krieger M. Abnormal lipoprotein metabolism and reversible female infertility in HDL receptor (SR-BI)-deficient mice. J Clin Invest. 2001;108(11):1717-1722.

9. Fuchs B, Muller K, Paasch U, et al. Potential Markers of Diseases and Infertility? Mini-Reviews in Medicinal Chemistry. 2012;12(1):74-86.

10. Oborna I, Wojewodka G, De Sanctis JB, et al. Increased lipid peroxidation and abnormal fatty acid profiles in seminal and blood plasma of normozoospermic males from infertile couples. Hum Reprod. 2010;25(2):308-316.

11. Chavarro JE, Toth TL, Wright DL, et al. Body mass index in relation to semen quality, sperm DNA integrity, and serum reproductive hormone levels among men attending an infertility clinic. Fertil Steril. 2009;93(7):2222-2231.

12. MacDonald AA, Herbison GP, Showell M, et al. The impact of body mass index on semen parameters and reproductive hormones in human males: a systematic review with meta-analysis. Hum Reprod Update. 2010;16(3):293-311.

13. Stouffer RL, Xu F, Duffy DM. Molecular control of ovulation and luteinization in the primate follicle. Front Biosci. 2007;12:297-307.

14. Simpson ER, Rochelle DB, Carr BR, et al. Plasma lipoproteins in follicular fluid of human ovaries. J Clin Endocrinol Metab. 1980;51(6):1469-1471.

15. Sato N, Kawamura K, Fukuda J, et al. Expression of LDL receptor and uptake of LDL in mouse preimplantation embryos. Mol Cell Endocrinol. 2003;202(1-2):191-194.

16. WHO. Laboratory Manual for the Examination of Human Semen and Sperm-cervical Mucus Interaction. Cambridge: Cambridge, University Press, USA. 2010.

17. Rotterdam ESHRE/ASRM-Sponsored PCOS Consensus Workshop Group. Revised 2003 consensus on diagnostic criteria and long term health risks related to polycystic ovary syndrome (PCOS). Fertil Steril. 2004;81(1):19-25.

18. Ozatik O, Aydin Y, Hassa H, et al. Relationship between oxidative stress and clinical pregnancy in assisted reproductive technology treatment cycles. J Assist Reprod Genet. 2013;30(6):765-772.
19. Garcia-Velasco JA, Isaza V, Caligara C, et al. Factors that determine discordant outcome from shared oocytes. Fertil Steril. 2003;80(1):54-60.

20. Jozwik M, Wolczynski S, Jozwik M, et al. Oxidative stress markers in preovulatory follicular fluid in humans. Mol Hum Reprod. 1999;5(5):409-413.

21. Folch J, Lees M, Sloane Stanley GH. Simple method for the isolation and purification of total lipids from animal tissues. $J$ Biol Chem. 1957;226(1):497-509.

22. Schlenk H, Gellerman J. Esterification of fatty acids with diazomethane on a small scale. Anal Chem. 1960;32(11):1412-1414.

23. Sergeant S, Ruczinski I, Ivester P, et al. Impact of methods used to express levels of circulating fatty acids on the degree and direction of associations with blood lipids in humans. Br J Nutr. 2016;115(2):251-261.

24. Huacuja L, Delgado NM, Calzada L, et al. Exchange of lipids between spermatozoa and seminal plasma in normal and pathological human semen. Arch Androl. 1981;7(4):343-349.

25. Sebastian SM, Selvaraj S, Aruldhas MM, et al. Pattern of neutral and phospholipids in the semen of normospermic, oligospermic and azoospermic men. J Reprod Fertil. 1987;79(2):373-378.

26. Sheriff DS. The lipid composition of human testis in patients with bilateral varicocele as cause of infertility. Andrologia. 1982;14(2):150-153.

27. Argov-Argaman N, Mahgrefthe K, Zeron Y, et al. Variation in lipid profiles within semen compartments - the bovine model of aging. Theriogenology. 2013;80(7):712-721.

28. Casado ME, Pastor O, Mariscal P, et al. Hormone sensitive lipase deficiency disturbs the fatty acid composition of mouse testis. Prostaglandins Leukot Essent Fatty Acids. 2013;88(3):227-233.

29. Tavilani H, Doosti M, Nourmohammadi I, et al. Lipid composition of spermatozoa in normozoospermic and asthenozoospermic males. Prostaglandins Leukot Essent Fatty Acids. 2007;77(1):45-50.

30. Tavilani H, Doosti M, Abdi K, et al. Decreased polyunsaturated and increased saturated fatty acid concentration in spermatozoa from asthenozoospermic males as compared with normozoospermic males. Andrologia. 2006;38(5):173-178.

31. Aksoy Y, Aksoy H, Altinkaynak K, et al. Sperm fatty acid composition in subfertile men. Prostaglandins Leukot Essent Fatty Acids. 2006;75(2):75-79.

32. Keber R, Rozman D, Horvat S. Sterols in spermatogenesis and sperm maturation. J Lipid Res. 2013;54(1):20-23.

33. Nolan JP, Hammerstedt RH. Regulation of membrane stability and the acrosome reaction in mammalian sperm. FASEB J. 1997;11(8):670-682.

34. Rana AP, Misra S, Majumder GC, et al. Phospholipid asymmetry of goat sperm plasma membrane during epididymal maturation. Biochim Biophys Acta. 1993;1210(1):1-7.

35. Scolari S, Müller K, Bittman R, et al. Interaction of mammalian seminal plasma protein $\mathrm{PDC}-109$ with cholesterol: implications for a putative CRAC domain. Biochemistry. 2010;49(42):9027-9031.

36. Masson D, Drouineaud V, Moiroux P, et al. Human seminal plasma displays significant phospholipid transfer activity due to the presence of active phospholipid transfer protein. Mol Hum Reprod. 2003;9(8):457-464.

37. Hagiuda J, Ishikawa H, Furuuchi $\mathrm{T}$, et al. Relationship between dyslipidaemia and semen quality and serum sex hormone levels: an infertility study of 167 Japanese patients. Andrologia . 2014;46(2):131-135. 
38. Okamura $\mathrm{H}$, Katabuchi $\mathrm{H}$, Ohba T. What we have learned from isolated cells from human ovary? Mol Cell Endocrinol. 2003;202(1-2):37-45.

39. Stouffer RL, Xu F, Duffy DM. Molecular control of ovulation and luteinization in the primate follicle. Front Biosci. 2007;12:297-307.

40. Robker RL, Akison LK, Bennett BD, et al. Obese women exhibit differences in ovarian metabolites, hormones, and gene expression compared with moderate-weight women. J Clin Endocrinol Metab. 2009;94(5):1533-1540
41. Yang X, Wu LL, Chura LR, et al. Exposure to lipid-rich follicular fluid is associated with endoplasmic reticulum stress and impaired oocyte maturation in cumulus-oocyte complexes. Fertil Steril. 2012;97(6):1438-1443. 